\title{
Effect of Colchicine on Inducible Nitric Oxide Synthase Activity and Nitric Oxide Production of Mice Induced by Aggregatibacter actinomycetemcomitans
}

\author{
Wihaskoro Sosroseno ${ }^{*}$, Endang Herminajeng1 ${ }^{1}$ Phillip S. Bird ${ }^{2}$ \\ ${ }^{1}$ Faculty of Dentistry, AIMST University, Bedong, Kedah, Malaysia \\ ${ }^{2}$ School of Veterinary Science, The University of Queensland, Gatton, Queensland, Australia \\ Email: *wihassosroseno@gmail.com
}

How to cite this paper: Sosroseno, W., Herminajeng, E. and Bird, P.S. (2019) Effect of Colchicine on Inducible Nitric Oxide Synthase Activity and Nitric Oxide Production of Mice Induced by Aggregatibacter actinomycetemcomitans. Journal of Biosciences and Medicines, 7, 18-30. https://doi.org/10.4236/jbm.2019.712003

Received: November 1, 2019

Accepted: November 28, 2019

Published: December 2, 2019

Copyright $\odot 2019$ by author(s) and Scientific Research Publishing Inc. This work is licensed under the Creative Commons Attribution International License (CC BY 4.0).

http://creativecommons.org/licenses/by/4.0/

c) (i) Open Access

\begin{abstract}
Objective: Colchicine induced a non-protective $\mathrm{Th}_{2}$-like immunity in $\mathrm{Ag}$ gregatibacter actinomycetemcomitans-stimulated murine immune response. The aim of the present study was to determine whether colchicine affects inducible nitric oxide synthase (iNOS) activity and nitric oxide (NO) production in A. actinomycetemcomitans-immunized mice. Materials and $\mathrm{Me}$ thods: BALB/c mice were sham-immunized (group I) or immunized with heat-killed $A$. actinomycetemcomitans (group II-VII). Colchicine was injected intraperitoneally before (group III), on the same day of (group IV), or after (group V) the primary immunization and on the same day of (group VI) or after (group VII) the secondary immunization. In vitro, spleen cells from either sham- or heat-killed $A$. actinomycetemcomitan-immunized animals were cultured and stimulated with heat-killed $A$. actinomycetemcomitans in the presence or absence of colchicine with or without addition of L-arginine, Db-cAMP, forskolin or interferon- $\gamma$ (IFN- $\gamma$ ). The levels of splenic iNOS activity and both serum and culture supernatant NO levels were assessed. Results: The results showed that colchicine did inhibit both splenic iNOS activity and serum NO levels only when the drug was injected at the same time as the immunization (group IV and VI). Splenic iNOS activity and NO levels on antigen-stimulated spleen cell cultures were also suppressed by colchicine, even in the presence of L-arginine, Db-AMP or forskolin. IFN- $\gamma$ only partially restored iNOS activity and NO levels in the antigen and colchicine-treated spleen cell cultures. Conclusion: This study suggests, therefore, that colchicine may suppress the iNOS activity and NO production in $A$. actinomycetemcomitans-immunized mice in vivo and in vitro.
\end{abstract}




\section{Keywords}

Aggregatibacter actinomycetemcomitans, Colchicine, NO, iNOS, Mice

\section{Introduction}

Colchicine, an alkaloid extract from Colchicum (autumn crocus), is used to treat a diverse number of inflammatory conditions, such as Behçet's disease, acute gout, familial Mediterranean fever (FMF), pericarditis and other cardiovascular disorders [1]. This drug enhanced both antibody production [2] [3] and dendritic cell functions [4], but inhibited monocyte and polymorphonuclear cell migration [5] [6] and cell-mediated immunity [7]. It was previously demonstrated, furthermore, that colchicine down-regulates a $\mathrm{T}$ helper 1 (Th1)-like immune response both in animal models [8] [9] and humans [10]. Colchicine also suppressed the expression of inducible nitric oxide synthase (iNOS) and the production of nitric oxide (NO) in vitro by different cell types such as murine macrophages [11] and rat aortic smooth muscle cells [12] as well as in vivo experimental brain contusion in rats [13], suggesting that the anti-inflammatory properties of this drug may also be via its inhibitory effects on the NO production.

Catalyzed by three isoforms of NOS, i.e., neural NOS (nNOS), endothelial NOS (eNOS) and iNOS, L-arginine is metabolized into a gaseous molecule called nitric oxide (NO) which plays a crucial role in cardiovascular, neural and immune system [14]. Increased expression of iNOS in inflamed periodontal tissues in humans [15] [16] and in experimental periodontitis in animal models [17] [18] have been documented, suggesting that oral bacteria, such as Aggregatibacter actinomycetemcomitans [19], inducing periodontal tissue destruction may be responsible for the increased periodontal tissue-derived iNOS expression. Indeed, A. actinomycetemcomitans induced the production of NO by both murine macrophages [20] [21] [22] [23] and splenocytes [24] as well as human osteoblasts [25]. The induction of immune response to A. actinomycetemcomitans in mice both in vivo and in vitro was regulated by NO [26] [27] [28] [29]. The additional of colchicine in the cultures of spleen cells isolated from heat-killed $A$. actinomycetemcomitans immunized-immunized mice resulted in increased splenic-specific IgG1, IL-4 and cell proliferation but suppressed specific IgG2a and IFN- $\gamma$ levels [30]. This suggested that colchicine may stimulate a T-helper 2 (Th2)-like immunity specific to A. actinomycetemcomitans in vitro [30]. Furthermore, this previous report also showed that colchicine only administered on the same day as the immunization enhances serum-specific IgG1 and IL-4 levels, suppresses specific-IgG2a and IFN- $\gamma$ levels as well as DTH response, and delays healing of the A. actinomycetemcomitans-induced skin lesions, suggesting that colchicine may stimulate a non-protective Th2-like immunity in A. actinomycetemcomitans-induced infections in mice [30]. Since colchicine was reported to 
suppress both iNOS expression and NO production in rodents [11] [12] [13], the aim of the present study was, therefore, to test a hypothesis that colchicine may alter iNOS activity and NO levels in A. actinomycetemcomitans-induced mice both in vitro and in vivo.

\section{Materials and Methods}

\subsection{Bacterial and Antigen Preparation}

A. actinomycetemcomitans Y4 (serotype b) was grown in Todd-Hewitt broth supplemented with $1 \%(w / v)$ yeast extract (Difco Lab., MI) as described previously [21]. Bacteria were plated out onto blood agar to validate identity and purity. Bacteria were harvested by centrifugation, washed three times in sterile PBS and their purity was checked by Gram stain. A. actinomycetemcomitans was heat-killed at $105^{\circ} \mathrm{C}$ for 5 minutes and protein concentration was assessed by using a protein kit (Bio-Rad, Richmond, Va).

\subsection{Immunization Procedures}

Female BALB/c mice (6 to 8 weeks old) were divided into seven groups, each consisting of five mice [30]. Group I was injected intraperitoneally with $100 \mu \mathrm{l}$ of saline, whereas group II to VII were immunized intraperitoneally with $100 \mu \mathrm{g}$ of bacterial protein in $100 \mu \mathrm{l}$ of saline weekly for two weeks. Group III and IV were injected intraperitoneally with $100 \mu \mathrm{l}$ of saline containing colchicine (Sigma, St. Louis, $\mathrm{MO}$ ) at $1 \mathrm{mg} / \mathrm{kg}$ body weight three days before the primary immunization and on the same day of the primary immunization, respectively. Group V and VI were injected with colchicine solution three days after the primary immunization and on the same day of secondary immunization, respectively. Group VII was injected with colchicine solution three days after the secondary immunization. Sera were obtained from the blood collected from the tail vein one week after the last immunization. After sacrificed by $\mathrm{CO}_{2}$ asphyxiation, spleens were aseptically removed and single cell suspensions were prepared as described below. The experimental procedures were approved by the Animal Ethics Committee of Universiti Sains Malaysia Health Campus, Malaysia.

\subsection{Cell Cultures}

Mice were divided into two groups, each consisting of five mice. Mice were injected intraperitoneally with $100 \mu \mathrm{L}$ of saline alone (sham-immunized mice) or with $100 \mu \mathrm{L}$ of saline containing $100 \mu \mathrm{g}$ of heat-killed A. actinomycetemcomitans (immunized mice) weekly for two weeks. One week after the last immunization, all animals were sacrificed by $\mathrm{CO}_{2}$ asphyxiation and spleens were removed aseptically. Single cell suspension was prepared and suspended in RPMI-1640 medium containing $10 \%$ fetal calf serum and $1 \%$ penicillin-streptomycin. Colchicine dissolved in dimethyl sulfoxide was diluted in saline and filter-sterilized. Two hundred thousand cells in $100 \mu \mathrm{L}$ of medium were cultured in 96-well plates (Nunc, Roskilde, Denmark), added with various con- 
centration of colchicine and $10 \mu \mathrm{g}$ of heat-killed $A$. actinomycetemcomitans and then incubated for four days in an incubator in $5 \% \mathrm{CO}_{2}$ at $37^{\circ} \mathrm{C}$ [12]. In other experiments, the cell cultures were added with or without $100 \mu \mathrm{M}$ of L-arginine (Sigma) [31], 200 unit/ml of MuIFN- $\gamma$ (R\&D System, Minneapolis) [21], $10 \mu \mathrm{M}$ of dibutyryl cyclic adenosine monophosphate (Db-cAMP) (Sigma), a cAMP analog [32], or $10 \mu \mathrm{M}$ of forskolin (Sigma), an adenylyl cyclase activator, [32] in the presence of $10 \mu \mathrm{M}$ colchicine. The cell cultures stimulated with or without heat-killed $A$. actinomycetemcomitane were used as a positive or negative control, respectively. All cultures were in triplicates. The experimental procedures were approved by the Ethical Committee of Universiti Sains Malaysia, Malaysia

\subsection{Nitric Oxide Assay}

One hundred microliter of serum were mixed with $449 \mu \mathrm{l}$ of solution containing $0.25 \mathrm{U}$ of nitrate reductase, $2.5 \mu \mathrm{M}$ flavin adenine dinucleotide (FAD), $28 \mathrm{mM}$ of potassium phosphate ( $\mathrm{pH} 7.5$ ), $25 \mu \mathrm{M}$ of NADPH and incubated for 2 hours at $37^{\circ} \mathrm{C}[26]$. The solution was added with $5 \mu \mathrm{g}$ of lactate dehydrogenase, $0.1 \mathrm{mM}$ of pyruvate and $44.5 \mu \mathrm{l}$ of water and further incubated for 30 minutes at $37^{\circ} \mathrm{C}$.

The Griess reagent was used to determine the levels of serum and culture supernatant nitric oxide [21]. Briefly, equal volume of samples $(100 \mu \mathrm{l})$ and the Griess reagent ( $1 \%$ sulfanilamide, $0.1 \%$ naphthl ethylenediamine dihydrochloride in $2.5 \%$ phosphoric acid) were mixed and then read spectrophotometrically by using $\mu Q$ uant spectrophotometer (Biotek-Instrument Inc., Vermont, USA) at $540 \mathrm{~nm}$. A standard curve was prepared with sodium nitrite. All reagents were purchased from Sigma.

\section{5. iNOS Activity Assay}

The cells from the cultures and spleens were lysed by incubating with $100 \mu$ of $0.1 \%$ Triton $\mathrm{X}-100$ and shaken for $30 \mathrm{~min}$ at room temperature. The protein concentration of the cell lysates was measured using a protein kit (Bio-Rad). Fifty microgram of cell lysate were incubated for $120 \mathrm{~min}$ at $37^{\circ} \mathrm{C}$ in $100 \mu \mathrm{l}$ of 20 $\mathrm{mM}$ Tris- $\mathrm{HCl}$ ( $\mathrm{pH} 7.9$ ) containing $4 \mu \mathrm{M} \mathrm{BH}_{4}, 4 \mu \mathrm{M}$ FAD, $3 \mathrm{mM}$ dithiothreitol, 2 $\mathrm{mM}$ NADPH and $2 \mathrm{mM}$ l-arginine [26]. Lactate dehydrogenase $(20 \mathrm{U} / \mathrm{ml})$ was added to stop the reaction and the levels of nitrite were measured by the Griess reagent as described above. All reagents were purchased from Sigma

\subsection{Statistical Analysis}

A one-way analysis of variance followed by Fischer's least-squared differences was used statistically to analyze the data (SPSS Inc, Chicago, IL).

\section{Results}

\subsection{The Levels of Splenic iNOS Activity and Serum NO in Groups of Colchicine-Treated Mice}

Both serum NO levels and the splenic iNOS activity in all groups of animals 
were shown in Figure 1. The results showed that the levels of both splenic iNOS activity and serum NO in group II-VII were significantly higher than those in group I $(\mathrm{P}<0.05)$ (Figure 1). However, the levels of both splenic iNOS activity and serum NO in group IV and VI were significantly lower than those in group II, III, V and VII $(\mathrm{P}<0.05)$.

\subsection{The Levels of iNOS Activity and NO Production in Cell Cultures}

When cell cultures were stimulated with heat-killed A. actinomycetemcomitans, the levels of both iNOS activity and NO levels in the cultures of the immunized cells were higher than those in the cultures of sham-immunized cells $(\mathrm{P}<0.05)$ (Figure 2). Treatment with colchicine in the cell cultures resulted in a dose-dependent suppression of both iNOS activity and NO levels $(\mathrm{p}<0.05)$. L-arginine increased significantly the levels of both iNOS activity and NO production in the heat-killed $A$. actinomycetemcomitans-stimulated cell cultures failed to overcome the suppressive effects of colchicine on the antigen-stimulated cell cultures $(\mathrm{p}<0.05)$ (Figure 3$)$. Furthermore, when heat-killed A. actinomycetemcomitans-stimulated cell cultures treated with Db-cAMP or

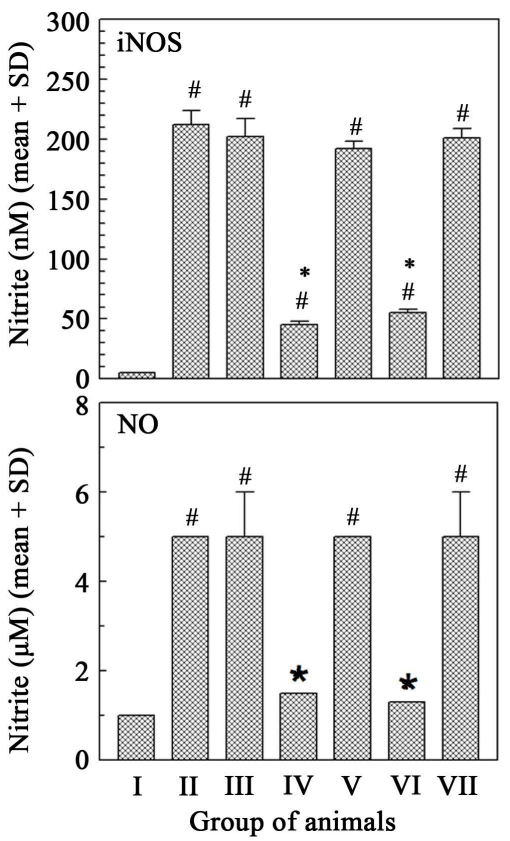

Figure 1. Effect of colchicine treatment on the levels of iNOS activity and NO production in mice immunized with $A$. actinomycetemcomitans in vivo. Group I was intraperitoneally injected with saline. Group II to VII were injected intraperitoneally with heat-killed A. actinomycetemcomitans weekly for 2 weeks. Group III and IV were injected intraperitoneally with colchicine 3 days before the primary antigen injection (week 1) and on the same day of the primary antigen injection, respectively. Group V and VI were injected with colchicine 3 days after the primary antigen injection and on the same day of secondary antigen injection (week 2), respectively. Group VII was injected with colchicine 3 days after the secondary antigen injection. $(\#)=$ significant difference to group $\mathrm{I}$ at $P<0.05$. $\left.{ }^{*}\right)=$ significant difference to group II at $P<0.05$. 

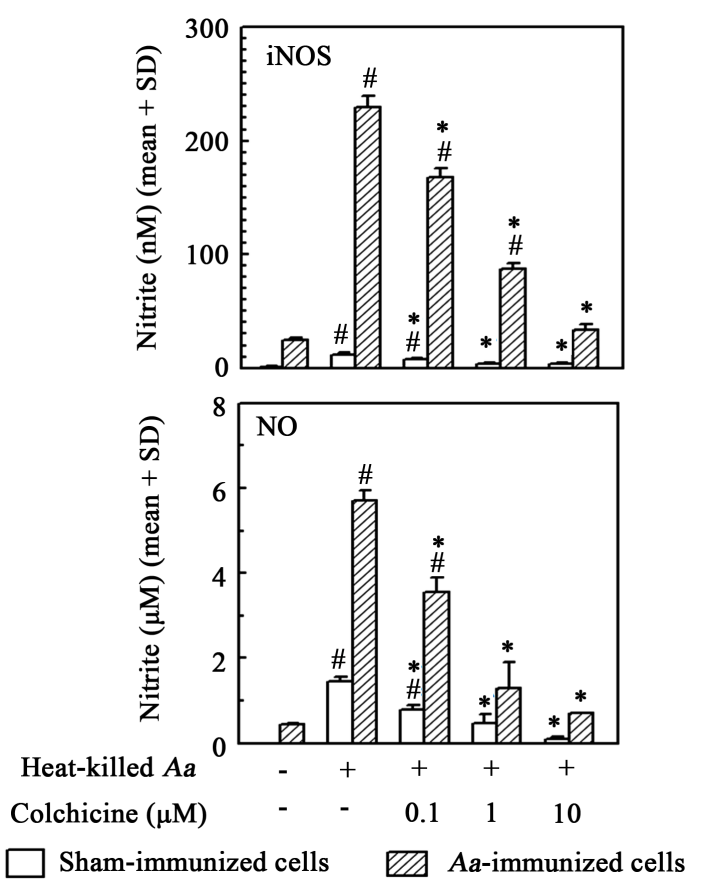

Figure 2. Effect of colchicine on the levels of iNOS activity and NO production by murine spleen cells stimulated with heat-killed $A$. actinomycetemcomitans ( $\mathrm{Aa}$ ) (10 $\mu \mathrm{g})$. (\#) $=$ significant difference to the negative control (cells only) at $P<0.05 .\left({ }^{*}\right)=$ significant difference to the positive control (cells + heat killed $A$ a) at $P<0.05$.
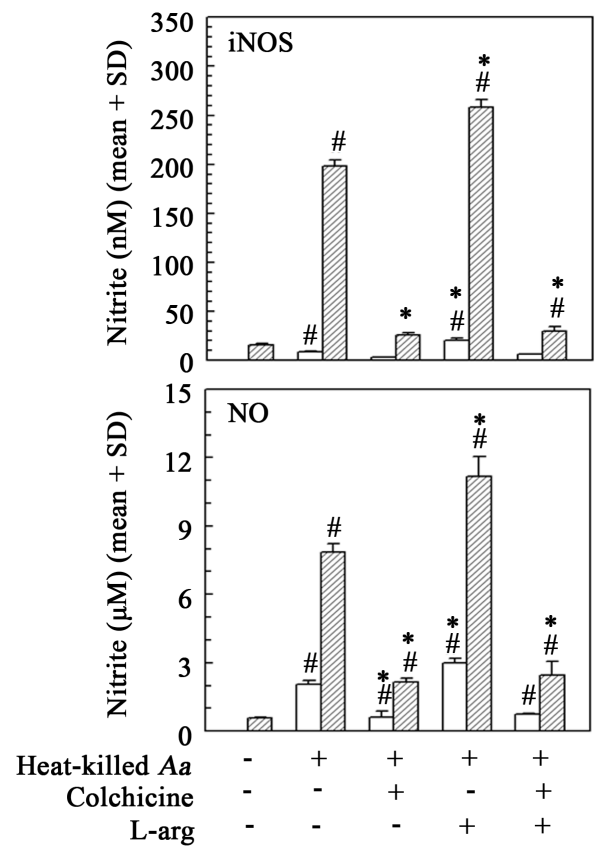

Sham-immunized cells

Aa-immunized cells

Figure 3. Effect of L-arginine (L-arg) $(100 \mu \mathrm{M})$ on the levels of iNOS activity and NO production by murine spleen cells stimulated with heat-killed A. actinomycetemcomitans (Aa) $(10 \mu \mathrm{g})$ with or without the presence of colchicine $(10 \mu \mathrm{M})$. $(\#)=$ significant difference to the negative control (cells only) at $P<0.05$. $\left(^{*}\right)=$ significant difference to the positive control (cells + heat killed $A a)$ at $P<0.05$. 
forskolin, both iNOS activity and NO production were significantly increased as compared with the antigen-stimulated cell cultures $(\mathrm{p}<0.05)$ (Figure 4). In sharp contrast, the iNOS activity and NO production by antigen-stimulated cells treated with Db-cAMP or forskolin in the presence of colchicine were inhibited $(p<0.05)$ (Figure 4). Interestingly, the results showed that the levels of both INOS activity and NO production by heat-killed $A$. actinomycetemcomitans-stimulated cell cultures in the presence of both colchicine and IFN- $\gamma$ were lower than those in the presence of IFN- $\gamma$ alone but much higher than those in the presence of colchicine alone $(\mathrm{p}<0.05)$ (Figure 5), suggesting that IFN- $\gamma$ may partially abrogate the suppressive effect of colchicine on iNOS activity and NO production of antigen-stimulated cell cultures.

\section{Discussion}

The present study showed that colchicine suppresses the levels of iNOS activity and NO production in the A. actinomycetemcomitans-immunized mice when this drug was administered at the same day of immunization. In sharp contrast, colchicine administered before or after the immunization failed to alter both iNOS activity and NO production of the immunized mice, suggesting that the effects of colchicine on the iNOS activity and NOS production in the immunized mice may be dependent on the timing of drug administration. The results of the
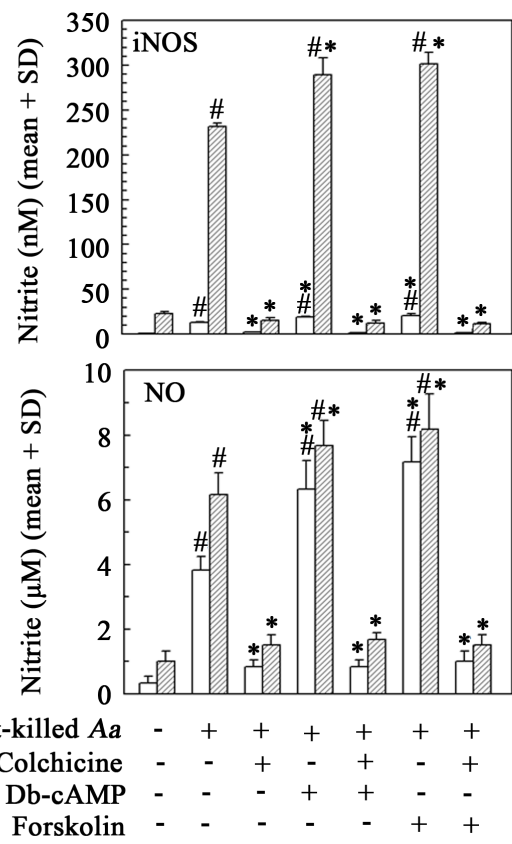

Sham-immunized cells

Aa-immunized cells

Figure 4. Effect of Db-cAMP $(10 \mu \mathrm{M})$, a cAMP analog, and forskolin $((10 \mu \mathrm{M})$, an adenylyl cyclase activator, on the levels of iNOS activity and NO production by murine spleen cells stimulated with heat-killed $A$. actinomycetemcomitans $(A a)(10 \mu \mathrm{g})$ with or without the presence of colchicine $(10 \mu \mathrm{M})$. (\#) = significant difference to the negative control (cells only) at $P<0.05 .\left({ }^{*}\right)=$ significant difference to the positive control (cells + heat killed $A a$ ) at $P<0.05$. 


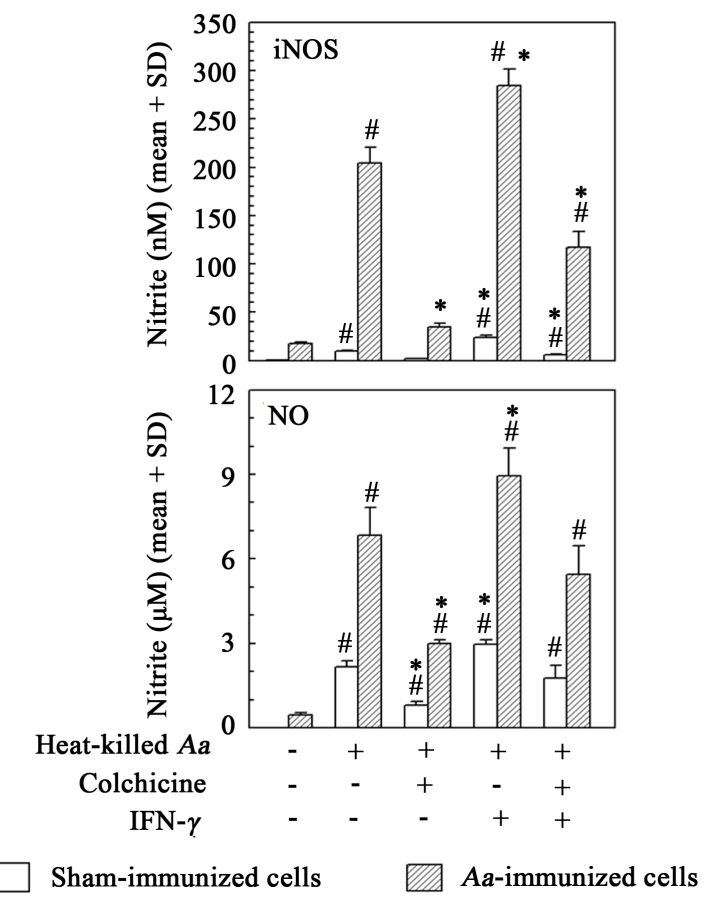

Figure 5. Effect of exogenous IFN- $\gamma(200 \mathrm{unit} / \mathrm{ml})$ on the levels of iNOS activity and NO production by murine spleen cells stimulated with heat-killed $A$. actinomycetemcomitans (Aa) $(10 \mu \mathrm{g})$ with or without the presence of colchicine $(10 \mu \mathrm{M}) .(\#)=$ significant difference to the negative control (cells only) at $P<0.05 .\left(^{*}\right)=$ significant difference to the positive control (cells + heat killed $A a$ ) at $P<0.05$.

present study are supported by the previous report showing that the both cellular and immune response of $A$. actinomycetemcomitans-immunized mice were suppressed by colchicine only when the drug was administered the same day of antigen immunization [30]. Further support can be drawn from the fact that suppression of iNOS expression in vivo by colchicine during experimental brain contusion occurred [13]. However, the exact mechanism by which colchicine inhibited both iNOS activity and NO levels of A. actinomycetemcomitans-immunized mice in vivo seen in the present study needs to be elucidated. It seems plausible that colchicine with its ability to inhibit cell microtubule polymerization might prevent the activation of $A$. actinomycetemcomitans-induced murine iNOS activity and hence, suppress both iNOS and NO levels in vivo [2] [3] [30]. Alternatively, the presence of colchicine at the same time as antigen immunization seen in the present study might suppress the production of Th1 cell-derived IFN- $\gamma$ but enhance Th2 cell-derived interleukin-4 [8] [9] [10] [30], resulting in the inhibition of iNOS activity and NO production. This colchicine-induced suppression of iNOS activity and NO production on A. actinomycetemcomitans-immunized mice in vivo is also shown by the results showing that the iNOS activity and NO production by $A$. actinomycetemcomitans-stimulated spleen cells derived from the immunized mice were suppressed by colchicine. Similar results have been reported that iNOS activity in macrophages and aortic smooth muscle cells was reduced by colchicine [11] [12]. 
Therefore, these results demonstrate that colchicine may be capable to inhibiting iNOS activity and NO production by $A$. actinomycetemcomitans-immunized mice in vivo and in vitro.

That previous study showing up-regulatory function of exogenous L-arginine on the production of NO by $P$. gingivalis-stimulated murine macrophages [31] is well supported by the present study. However, adding L-arginine into heat killed A. actinomycetemcomitans-stimulated murine spleen cell cultures seen in the present study failed to overcome the suppressive effects of colchicine on iNOS activity and/or NO production, suggesting deactivation of signal transduction generating iNOS activity but not lack of substrate. Similarly, exogenous cAMP analog and an adenylyl cyclase activator also failed to eliminate the suppressive effect of colchicine on iNOS activity and NO production by heat killed A. actinomycetemcomitans-stimulated murine cells, suggesting that colchicine may cause silence of the cAMP pathway in the antigen-stimulated murine cells and hence fail to induce iNOS activity and NO production. The cAMP signaling pathway is indispensable on the induction and regulation of iNOS activity [33]. Therefore, the present results support the notion that suppression of both iNOS activity and NO production by heat killed $A$. actinomycetemcomitans-stimulated murine cells may be due to the failure of signal transduction to generate iNOS protein activitiy as a result of colchicine-induced microtubule depolymerization (Figure 6). Indeed, colchicine did not interfere the iNOS mRNA transcription as previously reported [11]. Further studies to delineate this assumption are certainly needed.

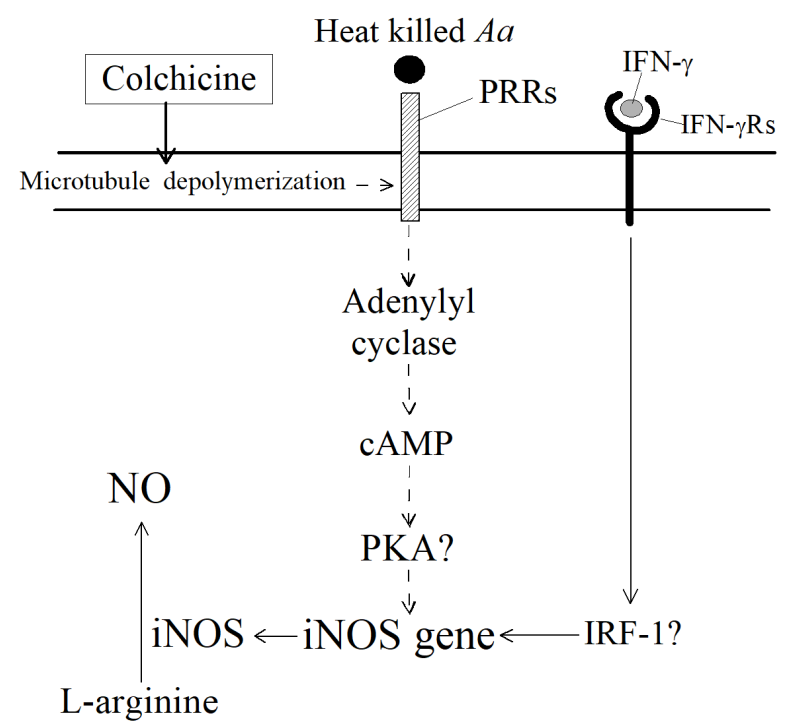

Figure 6. A simplified model of the effect of colchicine on iNOS activity and NO production by mice induced by $A$. actinomycetemcomitans $(A a)$. Colchicine causes cellular microtubule depolymerization resulting in failure of the cAMP-PKA signaling pathway and hence inhibition of iNOS activity and NO production. Despite colchicine-induced microtubule depolymerization, IFN- $\gamma$, possibly via the activation of IRF-1, is still able to partially stimulate iNOS activation and NO production, however. Note: Solid arrow $=$ activation signal. Broken arrow $=$ deactivation signal. IRF-1 = interferon regulatory factor 1 , $\mathrm{PKA}=$ protein kinase $\mathrm{A}, \mathrm{PRRs}=$ pattern recognition receptors. 
That IFN- $\gamma$ only partially abrogated the suppressive effects of colchicine on iNOS activity and NO production of antigen - stimulated cell cultures is of interest. The exact explanation of the results of the current study is unclear, however. IFN- $\gamma$ is known to involve the binding of IRF-1 on IRF-E in the iNOS promoter, leading to iNOS gene transcription [34]. Therefore, the results of the present study may be explained that whilst colchicine did inhibit cellular microtubule polymerization thereby preventing iNOS activity, exogenous IFN- $\gamma$ even in the presence of colchicine was still capable of partially inducing iNOS activity via the role of IRF-1, independently (Figure 6). This contention remains to be further investigated, however.

The implication of the present study in the pathogenesis of periodontal disease in humans remains hypothetical. The results of the present study showed that colchicine administration in $A$. actinomycetemcomitans-immunized mice significantly inhibits iNOS activity and NO production both in vivo and in vitro. Colchicine is used for treatment and prophylaxis of acute gout and inflammatory diseases such as Behçet's disease [1]. Indeed, severity of periodontal disease in patients with Behçet's disease appeared to be significantly increased [35] [36]. It remains, however, to be further studied whether colchicine given to Behçet's diseased patients concurrently exhibiting severe periodontal disease would adversely accelerate the course of the latter disease via suppression of iNOS activities and NO production.

\section{Conclusion}

The present study showed that colchicine given only on the same day as the immunization with heat-killed $A$. actinomycetemcomitans in mice inhibits iNOS activity and serum NO levels in vivo. Additional of L-arginine, Db-cAMP or forskolin failed to overcome the suppressive effects of colchicine on iNOS activity and NO production in A. actinomycetemcomitans-stimulated murine spleen cell cultures. However, exogenous IFN- $\gamma$ was able to partially restore the levels of iNOS activity and NO production in the antigen-stimulated cell cultures. The results of the present study indicate, therefore, that colchicine may suppress the iNOS activity and NO production of $A$. actinomycetemcomitans-induced mice in vivo and in vitro and that cellular microtubule polymerization may be prerequisite for A. actinomycetemcomitans-induced murine iNOS activity and NO production.

\section{Conflicts of Interest}

The authors declare no conflict of interest regarding the publication of this paper.

\section{References}

[1] Leung, Y.Y., Yao Hui, L.L. and Kraus, V.B. (2015) Colchicine-Update on Mechanisms of Action and Therapeutic Uses. Seminars in Arthritis and Rheumatism, 45, 341-350. https://doi.org/10.1016/j.semarthrit.2015.06.013 
[2] Shek, P.N. and Coons, A.H. (1978) Effect of Colchicine on the Antibody Response. I. Enhancement of Antibody Formation in Mice. The Journal of Experimental Medicine, 147, 1213-1227. https://doi.org/10.1084/jem.147.4.1213

[3] Titus, R.G. (1991) Colchicine Is a Potent Adjuvant for Eliciting T Cell Responses. The Journal of Immunology, 146, 4115-4119.

[4] Mizumoto, N., Gao, J., Matsushima, H., Ogawa, Y., Tanaka, H. and Takashima, A. (2005) Discovery of Novel Immunostimulants by Dendritic-Cell-Based Functional Screening. Blood, 106, 3082-3089. https://doi.org/10.1182/blood-2005-03-1161

[5] Dinarello, C.A., Chusid, M.J., Fauci, A.S., Gallin, J.I., Dale, D.C. and Wolff, S.M. (1976) Effect of Prophylactic Colchicine Therapy on Leukocyte Function in Patients with Familial Mediterranean Fever. Arthritis and Rheumatology, 19, 618-622. https://doi.org/10.1002/art.1780190315

[6] Valerius, N.H. (1978) In Vitro Effect of Colchicine on Neutrophil Granulocyte Locomotion. Assessment of the Effect of Colchicine on Chemotaxis, Chemokinesis and Spontaneous Motility, Using a Modified Reversible Boyden Chamber. Acta Pathologica et Microbiologica Scandinavica. Section B, 86, 149-154. https://doi.org/10.1111/j.1699-0463.1978.tb00024.x

[7] Mekori, Y.A., Baram, D., Goldberg, A. and Klajman, A. (1989) Inhibition of Delayed Hypersensitivity Reactions in Mice by Colchicine. I. Mechanism of Inhibition of Contact Sensitivity in Vivo. Cellular Immunology, 120, 330-340. https://doi.org/10.1016/0008-8749(89)90201-3

[8] Lyons, M.J., Amador, R., Petito, C., Nagashima, K., Weinreb, H. and Zabriskie, J.B. (1986) Inhibition of Acute Experimental Allergic Encephalomyelitis in Mice by Colchicine. The Journal of Experimental Medicine, 164, 1803-1808. https://doi.org/10.1084/jem.164.5.1803

[9] Alkalin, E., Hancock, W.W., Perico, N., Remuzzi, G., Imberti, O., Carperter, C.B. and Sayegh, M.H. (1995) Blocking Cell Microtubule Assembly Inhibits the Alloimmune Response in Vitro and Prolongs Renal Allograft Survival by Inhibition of Th1 and Sparing of Th2 Cell Function in Vivo. Journal of the American Society of Nephrology, 5, 1418-1425.

[10] Balkan, E., Bilen, H., Eyerci, N., Keleş, S., Kara, A., Akdeniz, N. and Dogan, H. (2018) Cytokine, C-Reactive Protein, and Heat Shock Protein mRNA Expression Levels in Patients with Active Behçet's Uveitis. Medical Science Monitor, 24, 1511-1516. https://doi.org/10.12659/MSM.907918

[11] Kirikae, T., Kirikae, F., Oghiso, Y. and Nakano, M. (1996) Microtubule-Disrupting Agents Inhibit Nitric Oxide Production in Murine Peritoneal Macrophages Stimulated with Lipopolysaccharide or Paclitaxel (Taxol). Infection and Immunity, 64, 3379-3384.

[12] Marczin, N., Jilling, T., Papapetropoulos, A., Go, C. and Catravas, J.D (1996) Cytoskeleton-Dependent Activation of the Inducible Nitric Oxide Synthase in Cultured Aortic Smooth Muscle Cells. British Journal Pharmacology, 118, 1085-1094. https://doi.org/10.1111/j.1476-5381.1996.tb15510.x

[13] Gahm, C., Holmin, S., Rudehill, S. and Mathiesen, T. (2005) Neuronal Degeneration and iNOS Expression in Experimental Brain Contusion Following Treatment with Colchicine, Dexamethasone, Tirilazad Mesylate and Nimodipine. Acta Neurochirurgica, 147, 1071-1084. https://doi.org/10.1007/s00701-005-0590-7

[14] Rodriguez, P.C., Ochoa, A.C. and Al-Khami, A.A. (2017) Arginine Metabolism in Myeloid Cells Shapes Innate and Adaptive Immunity. Frontiers in Immunology, 8, 93. https://doi.org/10.3389/fimmu.2017.00093 
[15] Özdemir, B., Özmeric, N., Elgün, S. and Barış, E. (2016) Smoking and Gingivitis: Focus on Inducible Nitric Oxide Synthase, Nitric Oxide and Basic Fibroblast Growth Factor. Journal of Periodontal Research, 51, 596-603. https://doi.org/10.1111/jre.12338

[16] Lucarini, G., Tirabassi, G., Zizzi, A., Balercia, G., Quaranta, A., Rubini, C., Aspriello, S.D. (2016) Uncoupling of Vascular Endothelial Growth Factor (VEGF) and Inducible Nitric Oxide Synthase (iNOS) in Gingival Tissue of Type 2 Diabetic Patients. Inflammation, 39, 632-642. https://doi.org/10.1007/s10753-015-0288-9

[17] Gyurko, R., Shoji, H., Battaglino, R.A., Boustany, G., Gibson, F.C., Genco, C.A., Stashenko, P. and Van Dyke, T.E. (2005) Inducible Nitric Oxide Synthase Mediates Bone Development and P. Gingivalis-Induced Alveolar Bone Loss. Bone, 6, 472-479. https://doi.org/10.1016/j.bone.2004.12.002

[18] Silva, M.J., Sousa, L.M., Lara, V.P., Cardoso, F.P., Júnior, G.M., Totola, A.H., Caliari, M.V., Romero, O.B., Silva, G.A., Ribeiro-Sobrinho, A.P. and Vieira, L.Q. (2011) The Role of iNOS and PHOX in Periapical Bone Resorption. Journal of Dental Research, 90, 495-500. https://doi.org/10.1177/0022034510391792

[19] Herbert, B.A., Novince, C.M. and Kirkwood, K.L. (2016) Aggregatibacter actinomycetemcomitans, a Potent Immunoregulator of the Periodontal Host Defense System and Alveolar Bone Homeostasis. Molecular Oral Microbiology, 31, 207-227. https://doi.org/10.1111/omi.12119

[20] Blix, I.J.S. and Helgeland, K. (1998) LPS from Actinobacillus actinomycetemcomitans and Production of Nitric Oxide in Murine Macrophages J774. European Journal of Oral Sciences, 106, 576-581. https://doi.org/10.1046/j.0909-8836.1998.eos106107.x

[21] Sosroseno, W., Barid, I., Herminajeng, E. and Susilowati, H. (2002) Nitric Oxide Production by a Murine Macrophage Cell Line (RAW264.7) Induced by Lipopolysaccharide from Actinobacillus actinomycetemcomitans. Oral Microbiology and Immunology, 17, 72-78. https://doi.org/10.1046/j.0902-0055.2001.00091.x

[22] Sosroseno, W., Bird, P.S. and Seymour, G.J. (2011) Nitric Oxide Production by a Murine Macrophage Cell Line (RAW264.7 Cells) Stimulated with Aggregatibacter actinomycetemcomitans Surface Associated Material. Anaerobe, 17, 240-251. https://doi.org/10.1016/j.anaerobe.2011.06.006

[23] Jo, W.S., Yee, S.T., Yoon, S., Nam, B.H., Do, E., Jung, B.S., Jeong, S.J., Hong, S.H., Yoo, Y.H., Kang, C.D., Lim, Y.J., Jeong, M.H. and Lee, J.D. (2006) Immunostimulating Factor Isolated from Actinobacillus actinomycetemcomitans Stimulates Monocytes and Inflammatory Macrophages. Microbiology and Immunology, 50, 535-542. https://doi.org/10.1111/j.1348-0421.2006.tb03823.x

[24] Sosroseno, W., Herminajeng, E., Budiarti, S. and Susilowati, H. (2002) Nitric Oxide Production by Murine Spleen Cells Stimulated with Lipopolysaccharide from Actinobacillus actinomycetemcomitans. Anaerobe, 8, 333-339. https://doi.org/10.1016/S1075-9964(03)00003-9

[25] Sosroseno, W., Bird, P.S. and Seymour, G.J. (2009) Nitric Oxide Production by a Human-Like Osteoblast Cell Line (HOS Cells) Stimulated with Aggregatibacter actinomycetemcomitans Lipopolysaccharide. Oral Microbiology and Immunology, 24, 50-55. https://doi.org/10.1111/j.1399-302X.2008.00475.x

[26] Sosroseno, W., Musa, M., Ravichandran, M., Fikri Ibrahim, M., Bird, P.S. and Seymour, G.J. (2007) Effect of L-N6-(1-Iminoethyl)-Lysine, an Inducible Nitric Oxide Synthase Inhibitor, on Murine Immune Response Induced by Actinobacillus actinomycetemcomitans Lipopolysaccharide. Journal of Periodontal Research, 42, 
124-130. https://doi.org/10.1111/j.1600-0765.2006.00925.x

[27] Sosroseno, W., Musa, M., Ravichandran, M., Ibrahim, M.F., Bird, P.S. and Seymour, G.J. (2008) Effect of Inhibition of Inducible Nitric Oxide Synthase on Murine Splenic Immune Response Induced by Aggregatibacter (actinobacillus) actinomycetemcomitans Lipopolysaccharide. European Journal of Oral Sciences, 116, 31-36. https://doi.org/10.1111/j.1600-0722.2007.00501.x

[28] Sosroseno, W., Bird, P.S. and Seymour, G.J. (2009) Effect of Exogenous Nitric Oxide on the Murine Splenic Immune Response Induced by Aggregatibacter actinomycetemcomitans Lipopolysaccharide. Anaerobe, 15, 95-98. https://doi.org/10.1016/j.anaerobe.2009.01.002

[29] Sosroseno, W., Bird, P.S. and Seymour, G.J. (2009) Effect of Exogenous Nitric Oxide on the Murine Immune Response Induced by Aggregatibacter actinomycetemcomitans Lipopolysaccharide. Journal of Periodontal Research, 44, 529-536. https://doi.org/10.1111/j.1600-0765.2008.01157.x

[30] Sosroseno, W. (2009) Effect of Colchicine on the Murine Immune Response Induced by Aggregatibacter actinomycetemcomitans. Biomedicine and Pharmacotherapy, 63, 221-227. https://doi.org/10.1016/j.biopha.2008.04.004

[31] Sosroseno, W., Herminajeng, E., Bird, P.S. and Seymmour, G.J. (2003) L-Arginine-Dependent Nitric Oxide Production of a Murine Macrophage-Like RAW 264.7 Cell Line Stimulated with Porphyromonas gingivalis Lipopolysaccharide. Oral Microbiology and Immunology, 18, 1-6. https://doi.org/10.1046/j.0902-0055.2003.00108.x

[32] Sosroseno, W., Musa, M., Ravichandran, M., Fikri Ibrahim, M., Bird, P.S. and Seymour, G.J. (2006) The Role of Cyclic-AMP on Arginase Activity by a Murine Macrophage Cell Line (RAW264.7) Stimulated with Lipopolysaccharide from Actinobacillus actinomycetemcomitans. Oral Microbiology and Immunology, 21, 347-352. https://doi.org/10.1111/j.1399-302X.2006.00300.x

[33] Galea, E. and Feinstein, D.L. (1999) Regulation of the Expression of the Inflammatory Nitric Oxide Synthase (NOS2) by Cyclic AMP. FASEB Journal, 13, 2125-2137. https://doi.org/10.1096/fasebj.13.15.2125

[34] Martin, E., Nathan, C. and Xie, Q.-W. (1994) Role of Interferon Regulatory Factor 1 (IRF-1) in Induction of Nitric Oxide Synthase. The Journal of Experimental Medicine, 180, 977-984. https://doi.org/10.1084/jem.180.3.977

[35] Akman, A., Kacaroglu, H., Donmez, L., Bacanli, A. and Alpsoy, E. (2007) Relationship between Periodontal Findings and Behçet's Disease: A Controlled Study. Jour nal of Clinical Periodontology, 34, 485-491. https://doi.org/10.1111/j.1600-051X.2007.01085.x

[36] Arabaci, T., Kara, C. and Ciçek, Y. (2009) Relationship between Periodontal Parameters and Behçet's Disease and Evaluation of Different Treatments for Oral Recurrent Aphthous Stomatitis. Journal of Periodontal Research, 44, 718-725.

https://doi.org/10.1111/j.1600-0765.2008.01183.x 